Brit. Heart Y., 1968, 30, 579.

\title{
Double Aortic Arch Associated with Complete Transposition of the Great Vessels ${ }^{\star}$
}

\author{
STANLEY M. HIGASHINO AND HERBERT D. RUTTENBERG
}

From the Division of Cardiology, Department of Pediatrics, University of California School of Medicine, Los Angeles, California 90024, U.S.A.

Double aortic arch is rarely associated with congenital intracardiac anomalies. To the best of our knowledge, the only case of double aortic arch associated with complete transposition of the great vessels was reported in 1837 by von Siebold. This report describes another case of this unusual combination and presents a review of the published reports of other cardiac defects described in conjunction with a double aortic arch.

\section{Case Report}

An 11-day-old Caucasian full-term baby girl was referred to the UCLA Medical Center in May 1965 for evaluation of cyanosis which had first been noted at 2 days of age, followed by progressive deterioration with increasing tachypnoea, dyspnoea, and tachycardia.

Physical examination revealed generalized and severe cyanosis with moderate dyspnoea. Weight was $3.4 \mathrm{~kg}$. Vital signs included a pulse rate of 144 , respiratory rate of 60 , temperature of $37.5^{\circ} \mathrm{C}$., blood pressure by flush of $80 \mathrm{~mm} . \mathrm{Hg}$ in the upper and lower extremities. Lungs were clear to auscultation and percussion. A grade $2 / 6$ systolic ejection murmur and a single accentuated second sound were audible at the left sternal border. The liver was $3 \mathrm{~cm}$. below the right costal margin. Pulses were normal.

Thoracic $x$-ray film (Fig. 1) was typical of transposition of the great vessels. The electrocardiogram was interpreted as showing right axis deviation, right atrial enlargement, and right ventricular hypertrophy.

Emergency angiocardiography from the saphenous vein and left atrium (Fig. 2) confirmed the clinical impression of complete transposition of the great vessels with an intact ventricular septum. A tortuous abnormality of the distal aortic arch was also noted.

Surgical creation of an atrial septal defect was performed at 13 days of age. There was transient improvement, but 10 hours after operation she developed

\footnotetext{
* Supported in part by a United States Public Health Service Grant.

9*
}

severe respiratory distress leading to cardiac arrest and death.

Necropsy (Fig. 3). The right and left lungs were congested. There was complete transposition of the great vessels, an intact ventricular septum, no pulmonary stenosis, and a large surgically created atrial septal defect. In addition, the ascending aorta bifurcated into equally patent left and right arches, each giving off subclavian and a common carotid artery. The arches encircled the trachea and oesophagus and joined posteriorly to form a left descending aorta. A patent ductus arteriosus connected the left arch to the left pulmonary artery.

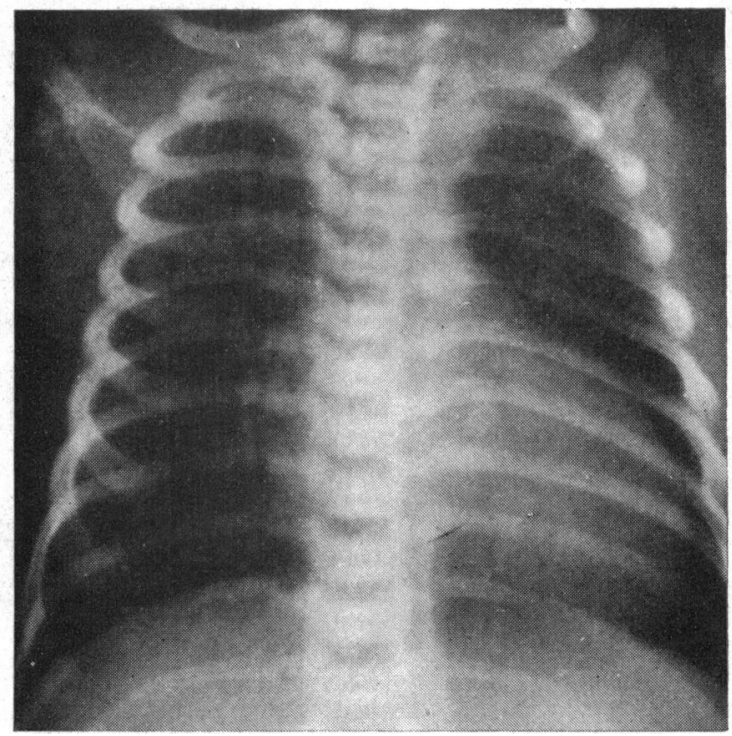

FIG. 1.-Chest $x$-ray film demonstrating typical findings of transposition of the great vessels: moderate cardiomegaly, an 'egg-shaped' cardiac contour, a narrow base, and increased 579 pulmonary vascularity. 
FIG. 2.-Left lateral angiocardiograms. (a) Venous angiogram shows opacification of the inferior vena cava (IVC), right atrium (RA), right ventricle (RV), and anteriorly placed ascending aorta (AA). The tortuous right (anterior arrow) and left (posterior arrow) arches unite to form the descending aorta (DA). (b) Left atrial angiocardiogram demonstrates the left atrium (LA), left ventricle (LV), and posteriorly placed pulmonary trunk (PT) and its branches.

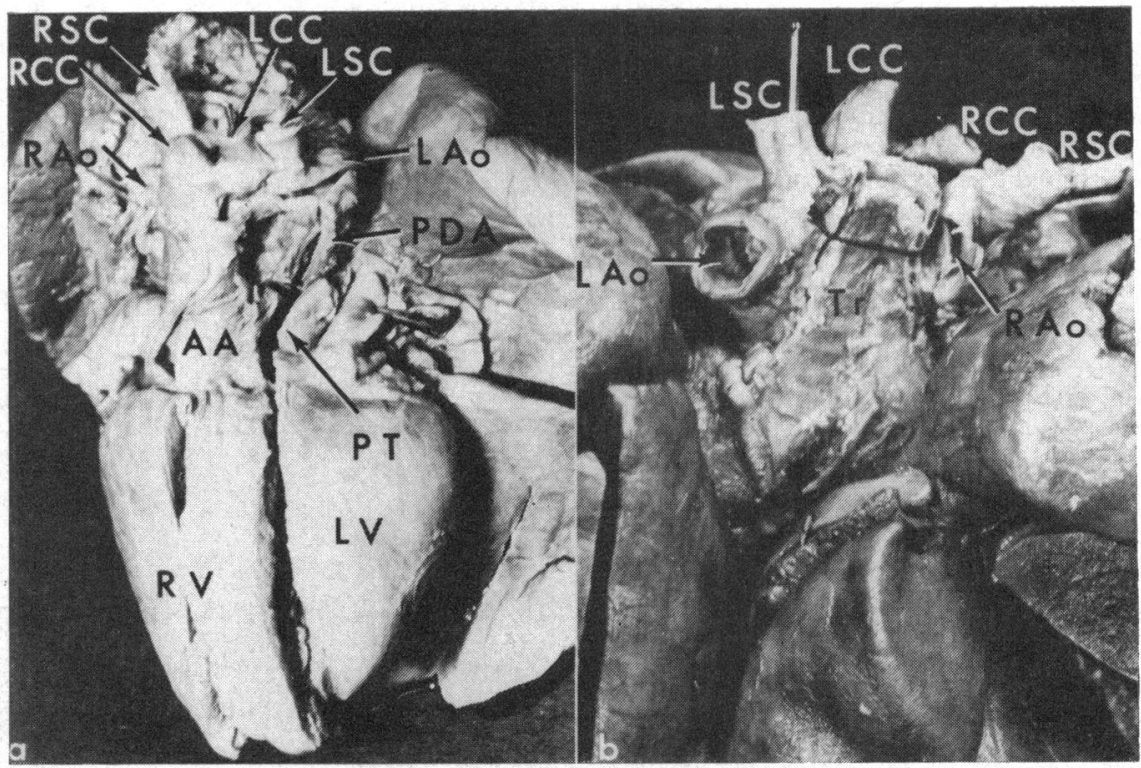

FIG. 3.-Pathological anatomy. (a) Anterior view of the heart and great vessels showing the ascending aorta (AA) arising from the right ventricle (RV) and the pulmonary trunk (PT) arising from the left ventricle (LV). The right aortic arch (RAo) gives rise to the right common carotid (RCC) and right subclavian (RSC) arteries while the left aortic arch (LAo) gives rise to the left common carotid (LCC) and left subclavian (LSC) arteries. A patent ductus arteriosus (PDA) connects the pulmonary trunk to the distal left aortic arch; b: Posterior view of the double aortic arch which demonstrates the vascular ring encircling the trachea ( Tr). The right arch continues around the trachea and oesophagus and joins the left arch. The aorta descended on the left (not shown). 


\section{Discussion}

A double aortic arch (both arches patent) is rarely associated with other intracardiac anomalies. Of the 16 cases reported (including the case reported herein), 14 had a cyanotic cardiac malformation. The associated cardiac anomalies were: tetralogy of Fallot in 11 (Blalock, 1948; Griswold and Young, 1949; Bahnson and Blalock, 1950; Dodrill, 1952; Blumenthal and Ravitch, 1957; Edwards et al., 1965), complete transposition of the great vessels in 2 (von Siebold, 1837), and single cases of double outlet right ventricle with anomalous systemic venous return (Harris and Whitney, 1927), atrial septal defect (Abbott, 1936), and persistent common atrioventricular canal (Gasul, Arcilla, and Lev, 1966).

Although most patients with a double aortic arch present with symptoms of tracheo-oesophageal obstruction, 9 of 11 cases in this review in which symptoms were recorded had no such symptoms. The signs and symptoms of tracheo-oesophageal obstruction, however, may have been overlooked or misinterpreted as a result of the dominating clinical features of the intracardiac lesion. The presence of a vascular ring in addition to the intracardiac defect may be an important complicating factor in the operative procedure and post-operative course. The post-operative respiratory problems in the present patient may have been contributed to by the vascular ring.

\section{Summary}

A case of double aortic arch associated with complete transposition of the great vessels is reported and a review of the published reports of other intracardiac anomalies is presented. Associated cardiac malformations almost invariably are of a cyanotic nature, most commonly a tetralogy of Fallot.

\section{References}

Abbott, M. E. (1936). Atlas of Congenital Heart Disease. The American Heart Association, New York.

Bahnson, H. T., and Blalock, A. (1950). Aortic vascular rings encountered in the surgical treatment of congenital pulmonic stenosis. Ann. Surg., 131, 356.

Blalock, A. (1948). Surgical procedures employed and anatomical variations encountered in the treatment of congenital pulmonic stenosis. Surg. Gynec. Obstet., 87, 385.

Blumenthal, S., and Ravitch, M. M. (1957). Seminar on aortic vascular rings and other anomalies of the aortic arch. Pediatrics, 20, 896.

Dodrill, F. D. (1952). Double aortic arch. Surgery, 31, 204.

Edwards, J. E., Carey, L. S., Neufeld, H. N., and Lester, R. G. (1965). Congenital Heart Disease. W. B. Saunders, Philadelphia.

Gasul, B. M., Arcilla, R. A., and Lev, M. (1966). Heart Disease in Children: Diagnosis and Treatment. J. B. Lippincott, Philadelphia.

Griswold, H. E., Jr., and Young, M. D. (1949). Double aortic arch. Pediatrics, 4, 751 .

Harris, H. A., and Whitney, C. (1927). The heart of a child aged nineteen months presenting right and left aortic arches with multiple anomalies of the heart and great vessels. Anat. Rec., 34, 221.

von Siebold, C. T. (1837). Aortenbogen, ringförmiger, bei einem neugebornen, blaustichtigen Kinde. Fournal für Geburtshülfe, Frauenzimmer-und-Kinderkrankheiten, 16, 294. 